\title{
Word formation by external motivation in Spanish and French
}

\section{[Formacion de palabras por motivacion externa en espanol y en frances]}

\author{
Diana Patricia Varela Cano
}

DOI: 10.18355/XL.2020.13.01.17

\begin{abstract}
To define the area of word formation, it is necessary to take into account that lexicon is included in morphology. Lexicon is the vocabulary of a language, region, activity, or branch of knowledge. While morphology deals with the internal structure of the word, etymology studies the origin, evolution and growing process of the lexical fund of a language. This process of lexical enrichment may be the result of internal and external causes or motivation. External motivation refers to foreign words being borrowed or taken over by a linguistic system that does not have a word to designate that specific concept. Spanish takes over such expressions in two different ways, sometimes keeping their original structure and some others assimilating it.
\end{abstract}

Key words: lexicon, external motivation, borrowings, foreign words, neologisms, phraseological expressions

\begin{abstract}
o
Para definir el área de la formación de las palabras hay que tener en cuenta que dentro de la morfología se incluye el léxico. El léxico es el vocabulario, conjunto de palabras, de un idioma, o las que pertenecen al uso de una región, a una actividad determinada, a un campo semántico dado, etc. La morfología se dedica a la estructura interna de la palabra mientras que la etimología se ocupa del estudio del origen, evolución y procesos enriquecedores del fondo léxico de la lengua. Este proceso de enriquecimiento léxico puede estar originado por una motivación interna o externa. La motivación externa se refiere a palabras extranjeras prestadas por un sistema lingüístico que no tiene una palabra con la cual designar ese concepto específico. Al español estos préstamos pueden incorporarse de dos formas, ya sea manteniendo su estructura original o asimilándose al español.
\end{abstract}

Palabras clave: léxico, motivación externa, préstamos, extranjerismos, neologismos, expresiones fraseológicas

\section{Introducción}

El presente trabajo tiene por objetivo el estudio de la formación de palabras en español y en francés por motivación externa creadas mediante los préstamos, neologismos, extranjerismos y expresiones fraseológicas. Nuestro estudio está enfocado desde un punto de vista morfológico; los aspectos que analizamos han sido elegidos partiendo de los rasgos teóricos que hemos presentado y que hemos acompañado con ejemplos. Nuestra finalidad es despertar el interés en nuestros estudiantes de la Universidad de Economía de Bratislava que aprenden español como lengua extranjera, por el estudio del léxico en el sector de la economía, para una mejor comprensión e interpretación de textos relacionados con la economía. Para esto hemos elegido la revista: La Nota Económica, del mes de Julio de 2017 de la cual hemos analizado y extraído términos especializados en sectores económicos.

\section{Formación de palabras en español.}

La lengua es un sistema con una estructura en la que sus componentes tienen su propia característica, y a la vez, existe entre ellos una interdependencia. Estos

XLinguae, Volume 13 Issue 1, January 2020, ISSN 1337-8384, eISSN 2453-711X 
componentes son: el fonético, la semántica, la gramática y el pragmático. En nuestro estudio, nos centraremos en el componente de la semántica, la cual abarca los planos de la morfología y la sintaxis. La morfología se dedica a la estructura interna de la palabra, mientras que la sintaxis se ocupa de las reglas que rigen la combinación de estas palabras originando oraciones. Es decir, la semántica estudia el significado, sentido de las palabras, y su unión en frases y expresiones. A su vez, la morfosintaxis es una disciplina estructura que comprende dos planos integrados de la lengua: la morfología y la sintaxis. Estas disciplinas tienen como objetivo principal el análisis descriptivo de las diferentes construcciones lingüísticas, como resultado de distintos procesos y unidades concretas del sistema.

En muchas ocasiones nos sorprende escuchar términos o palabras que nos pueden parecer extrañas, y por qué no hasta graciosas o inconcebibles. Esto gracias a la gran riqueza, amplitud y libertad del léxico de las personas. Ahora bien, debemos recordar que el castellano o español se derivó del latín, pero que también ha recibido influencia lingüística de otras lenguas como: griego, árabe, alemán, lenguas indígenas amerindias y de otras. De igual manera, debido a los alcances tecnológicos, el hombre se ha visto obligado a inventar palabras para designar algún objeto, animal o cosa, convirtiéndose así en neologismos. El castellano o español es hablado por más de 550 millones de personas en el mundo, de aquí que no todos en los países de habla hispana hablemos de la misma manera. Esto lo podemos ver en la amplia utilización de sufijos, prefijos, lexemas con los que se forman un sinnúmero de palabras que pueden llegar a variar en su categoría. Sobre esto hablaremos más adelante en la parte dedicada a la formación de palabras.

Para definir el área de la formación de las palabras hay que tener en cuenta que dentro de la morfología se incluye el léxico. El léxico es el vocabulario, conjunto de palabras de un idioma, o las que pertenecen al uso de una región, a una actividad determinada, a un campo semántico dado, etc. Diccionario de la lengua española, (DEL), Real Academia Española (http://dle.rae.es/?id=ND3Rym3, 10.10.2017). Como explica Urrutia y Candia (1997: 12) dentro del léxico se incluye la morfología ya que lo caracteriza mediante las variaciones formales (flexiones) que expresan categorías y relaciones gramaticales. Ahora, considerando solo el aspecto funcional y categorial, la morfología se incluye dentro de la morfosintaxis.

La etimología se ocupa del estudio del origen, evolución y procesos enriquecedores del fondo léxico de la lengua. El proceso de enriquecimiento léxico puede estar originado por una motivación interna o externa. La Motivación interna puede ser morfológica (composición [sinapsia, disyunción, contraposición, yuxtaposición], derivación [prefijos, sufijos, interfijos], parasíntesis, acortamiento [apócope, abreviaturas, siglas, acrónimos, aféresis]); fónica (onomatopéyicas); semántica (revitalización, polisémica). La motivación externa se refiere a los préstamos externos del sistema lingüístico, esto se debe a la ausencia de una palabra para designar un significado. Al igual que en español, en francés estos préstamos pueden incorporarse de dos formas, ya sea manteniendo su estructura original: el marketing - le marketing, el jet set - le jet set, etc. o asimilándose al español: filme, tique, etc. Ver esquema 1 


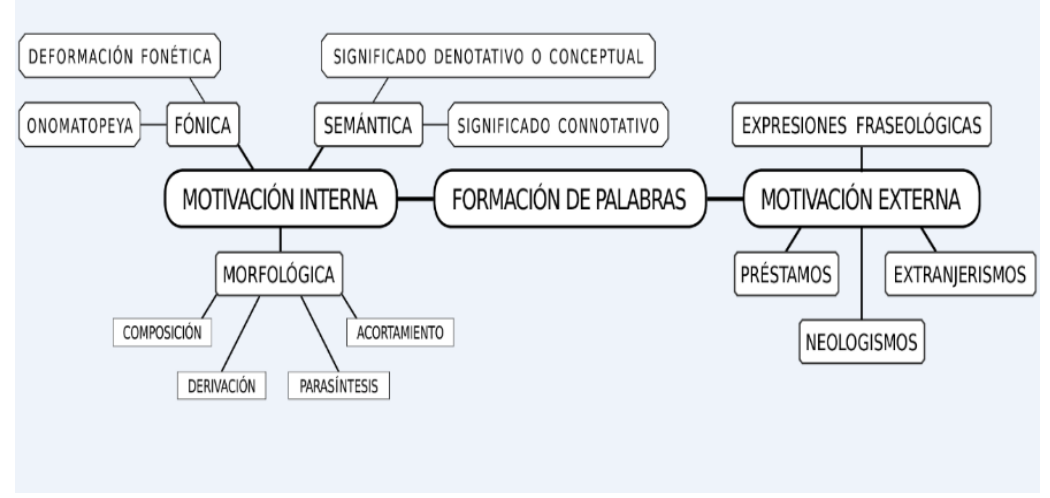

\section{Esquema 1: Formación de palabras}

\section{Motivación externa en la formación de palabras}

Es cuando palabras existentes en una lengua dan lugar a la formación de nuevos significantes. Estas palabras existentes pueden ser de otros sistemas lingüísticos y tomados de estos como préstamos. Ahora bien, existen préstamos que conservan la estructura de su lengua original mientras que hay otros cuya estructura se adapta a la lengua receptora. Esto da paso a lo que conocemos como préstamo (término adaptado) y extranjerismo (término no adaptado). En el primer momento en el proceso de introducción de estos préstamos a otra lengua, estos tienen algunos inconvenientes, ya que como dice Gómez Capuz J. (2009:4), en principio estos préstamos están limitados al lenguaje técnico del cual preceden, no son conocidos ni comprendidos por los hablantes de la lengua receptora, al no haber sido todavía asimilados a la normativa de la lengua receptora, conservan tanto la grafía como la pronunciación original. En cuanto a esta situación, Gómez Capuz J. también explica que para los filólogos franceses es una discusión sobre si se trata de verdaderos préstamos o simplemente son extranjerismos, para lo cual utilizan algunas denominaciones para esta especial situación: 'palabras ocasionales', 'palabras casuales' o 'palabras-cita'. También señala que el término xenismo (en francés, xénisme) es otro de los utilizados, a pesar de la confusión que puede presentar dicho término en la misma filología francesa. Para algunos autores este término es un extranjerismo que conserva su grafía original, pero según otros autores, puede designar una realidad propia de una cultura extranjera y que no está adaptada a la vida y cultura francesas, sin negarle su condición de préstamo, por eso, pueden presentar algunos ejemplos de xenismos, préstamos asimilados como shérif (< sheriff) y calcos como anée sabbatique (< sabbatical leave 'año sabático'). Estos autores franceses presentan ejemplos del inglés norteamericano con el propósito de demostrar que es una cultura ajena. A estos xenismos de sentido etnológico se les identifican también como exotismos. Agrega que, a diferencia del francés, en la lengua española existe el término extranjerismo para designar el préstamo no asimilado y que se debería utilizar el término xenismo para casos más específicos en casos etnológicos y extralingüístico en aquellas situaciones de contacto interlingüísticos donde sea necesario (Gómez Capuz J.). El DLE define xenismo como un extranjerismo que conserva su grafía original (p. ej., software) (https://dle.rae.es/?w=xenismo+).

Los préstamos pueden incorporarse al español manteniendo su estructura original o asimilándose a este. Urrutia (1997: 13) dice que estas incorporaciones pueden ser de forma variada. Por tanto, podemos encontrar formas ya castellanizadas $c l u b$, o formas

XLinguae, Volume 13 Issue 1, January 2020, ISSN 1337-8384, eISSN 2453-711X 
que solo en la expresión lexicogenética morfológica se han incorporado al sistema, manteniendo la base léxica con la estructura extranjera chalecito, jazzista. De igual manera, afirma que las palabras extranjeras suelen afectar la fonología tradicional del español. Esto lo podemos notar en la acentuación de las de algunas palabras. Las palabras que se han incorporado deben acentuarse según las reglas del español, por ejemplo: béisbol, carné, casete, búnker, gánster, etc. Las palabras extranjeras que conservan su estructura original no se deben acentuar si en su idioma de procedencia no tiene ningún acento. Los extranjerismos no adaptados se deben escribir en cursiva, o entre comillas. Las diferencias entre préstamos y extranjerismos radican principalmente en las diferencias en algunas pautas con la lengua receptora tales como la asimilación gráfica, fónica y gramatical al igual. Otro aspecto que afecta la estructura fonológica del español son las terminaciones de muchos anglicismos en consonantes o grupos consonánticos no tolerados por la fonología española, por ejemplo: clip, flirt, flash, song. R. Lapesa (in Urrutia 1997: 13)

a. préstamo lingüístico, es un elemento, generalmente léxico, que una lengua toma de otra. DLE (http://dle.rae.es/?id=U73g6MY, 1.11.2017). Para Guerrero-Ramos (in Vela Candelas J. 2014: 35) un préstamo es todo rasgo lingüístico (de tipo léxico, sintáctico, semántico, morfológico, fonológico o formal) que un sistema lingüístico B (receptor) toma, adapta o traduce de un sistema lingüístico A (donante) y que previamente no existía en B. Ya en La Edad Media se empezaron a registrar préstamos de lenguas romances en el castellano gracias a los peregrinos que se dirigían a Santiago de Compostela. Así se introducen galicismos, catalanismos, portuguesismos, galleguismos, y principalmente latinismos, helenismos y arabismos. Con la conquista de América se incorporaron muchas palabras procedentes de lenguas indígenas. En los últimos siglos también se han introducido germanismos, y gracias a los avances científicos y técnicos la fuerza de los anglicismos se ha hecho presente.

b. extranjerismos, son palabras de una lengua extranjera que otra lengua toma. Es cierto que muchos extranjerismos enriquecen una lengua cuando la lengua receptiva no puede, con sus propias palabras, cubrir nuevas realidades. Aunque también es cierto que muchas veces la lengua receptora posee un equivalente. DLE (http://dle.rae.es/?id=HOauPO6, 1.11.2017) define extranjerismo lingüístico como un préstamo, especialmente el no adaptado. Los extranjerismos se pronuncian con ciertas características fonéticas propias de la lengua que los toma. En cuanto a su escritura y ortografía, en español, en el Diccionario panhispánico de dudas se ha adaptado muchos extranjerismos. Teniendo en cuenta lo anterior podemos decir que los extranjerismos se dividen en adaptados, no adaptados y especializados.

- extranjerismos adaptados, son los que se han adaptado principalmente, desde el punto de vista del número y ortográfico.

- tennis $\rightarrow$ tenis - tennis

- baseball $\rightarrow$ beisbol - baseball

- extranjerismos no adaptados, son palabras que conservan la grafía y pronunciación de la lengua receptora, y se escriben en cursiva.

- manager $\rightarrow$ manager - manager

- jezz $\rightarrow$ jazz - jazz

- extranjerismos especializados, estos se refieren a una realidad ajena y de la cual no hay un equivalente en la lengua receptora.

- scanner $\rightarrow$ escáner - scanner 
- hardware $\rightarrow$ hardware - hardware

- software $\rightarrow$ software - software

- bluetooth $\rightarrow$ bluetooth - bluetooth

- samurai $\rightarrow$ samurái - samouraï/samurai

- burka $\rightarrow$ burka - burqa / burka

- tãlibãn $\rightarrow$ talibán - taliban

c. neologismos, son palabras o expresiones nuevas que se han introducido recientemente en una lengua o que han sido creadas para designar conceptos nuevos. El DLE (http://dle.rae.es/?id=QOrQDkR, 1.11.2017) define neologismo como vocablo, acepción o giro nuevo en una lengua. Para Alvar Ezquerra M. (2007:13-15) los neologismos pueden ser de diferentes caracteres.

- denotativos, son los que surgen de la necesidad por la falta de denominación para lo nuevo que surge en el mundo.

- expresivos, son los que resultan por la voluntad individual para expresar de forma diferente una visión particular de la realidad extralingüística.

- estilísticos, son de carácter individual, por lo general se realizan en situaciones muy concretas, muestran la capacidad creativa del autor.

\section{Las expresiones fraseológicas}

El español, pese a ser uno de los idiomas más hablados en todo el mundo, conserva una considerable homogeneidad. Sin embargo, existen diferencias lingüísticas perceptibles entre sus dialectos, y especialmente entre España y Latinoamérica, por la lejanía entre estos lugares. A pesar de esto existen expresiones, frases y refranes que forman parte de la herencia lingüística de los diferentes países y regiones de habla hispana, como también los hay que son característicos para determinados países o regiones por las diferencias de tipo regional, nivel sociocultural de los hablantes, zonas rurales, urbanas, etc. Pero hay que aclarar que el factor cultural, y en especial la escolarización, es un elemento nivelador que influye en la homogenización de las lenguas.

La sabiduría popular se expresa y transmite de diferentes formas, una de ellas son los refranes, expresiones fijas denominadas modismos, frases hechas, lexías complejas o locuciones. Estas frases han surgido de la experiencia de la vida a través de los tiempos, se han transmitido principalmente de forma oral con versos y rimas elementales. Según Roberts (In Montero Martinez S. 2003: 123) "la fraseología es un nuevo término que designa unas realidades lingüísticas tan antiguas como las propias lenguas." Estas frases y expresiones fijas reflejan la idiosincrasia del pueblo que los utiliza y sirve para conocerlo más. Además, nos muestran la riqueza del vocabulario y la belleza de la lengua. Los refranes los encontramos al combinar varias palabras que funcionan como oración o elemento oracional, y cuyo sentido no corresponde a la suma de sus significados, por ejemplo: llueve a cántaros - il tombe des cordessino que sirven para expresar una sabiduría o un consejo.

La experiencia adquirida y el sentido común se resumen en los refranes, pero no siempre esas experiencias son iguales ni coherentes para todos, por eso, los refranes pueden representar una misma situación desde diferentes puntos de vista según convenga. Así, en la frase: ahogarse en un vaso de agua - se noyer dans un verre d'eau, no se debe entender en un sentido literal, sino que adquiere un significado específico asociado a otra circunstancia, en este caso concreto, los de no saber reaccionar ante una situación que en realidad no es muy complicada. En muchas ocasiones es necesaria la ayuda de un contexto comunicativo para poder interpretar su significado.

Los refranes y el refranero se han convertido en un objeto de estudio dando lugar a la

XLinguae, Volume 13 Issue 1, January 2020, ISSN 1337-8384, eISSN 2453-711X 
Paremiología que se encarga de su estudio, clasificándolos y ordenándolos en un tratado de refranes. Estas expresiones que se han ido recogiendo han recibido diferentes denominaciones, tales como frases hechas, expresiones fijas y unidades fraseológicas, entre otras. Todas ellas implican lo mismo, nosotros en adelante usaremos el término unidades fraseológicas. Con relación a ellas muchos autores se refieren como fraseología. El término "Fraseología" se compone de las raíces griegas frasis ('expresión', 'frase') y logos ('palabra', 'concepto') su significado originario era de 'ciencia que se ocupa de las expresiones y frases' o 'Estilística, ciencia de la expresión'. Este término se remonta al Humanismo tardío y desde un principio designa tanto el inventario de expresiones idiomáticas de una lengua como su estudio (Mellado Blanco, in Sciuto V. 502). El DLE (http://dle.rae.es/?id=IPhICME, 14.10.2017) la define como: Conjunto de modos de expresión peculiares de una lengua, de un grupo, de una época, actividad o individuo. Conjunto de frases hechas, locuciones figuradas, metáforas y comparaciones fijadas, modismos y refranes, existentes en una lengua, en el uso individual o en el de algún grupo. (1 y 4 acepción). Para Pastor Corbas (in Jiron Erwenne C. 2008: 4) las unidades fraseológicas son "unidades léxicas formadas por más de dos palabras gráficas en su límite inferior, cuyo nivel superior se sitúa en el nivel de la oración compuesta. Dichas unidades se caracterizan por su alta frecuencia de uso, y de coaparición de sus elementos integrantes; por su institucionalización, entendida en términos de fijación y especialización semántica; por su idiomaticidad y variación potencial; así como por el grado en el cual se dan todos estos aspectos en los distintos tipos".

\section{Clasificación de las unidades fraseológicas}

Realizar una clasificación de las unidades fraseológicas no ha sido fácil ya que son varios los criterios que se han tenido en cuenta según varios modelos de diferentes autores. Romero Ganuza P. (2006: 906) establece tres criterios para determinarlas: la estabilidad semántica-sintáctica, la idiomaticidad y la lexicalización y reproductividad. Nos orientamos por la clasificación hecha por Corpas Pastor (in Jirón Erwenne C. 2008: 5) quien propone combinar el criterio de enunciado con el de la fijación en la norma. Las unidades fraseológicas las clasifica de en tres esferas: Esfera I (colocaciones), Esfera II (locuciones) y Esfera III (enunciados fraseológicos). (Ver esquema 2)

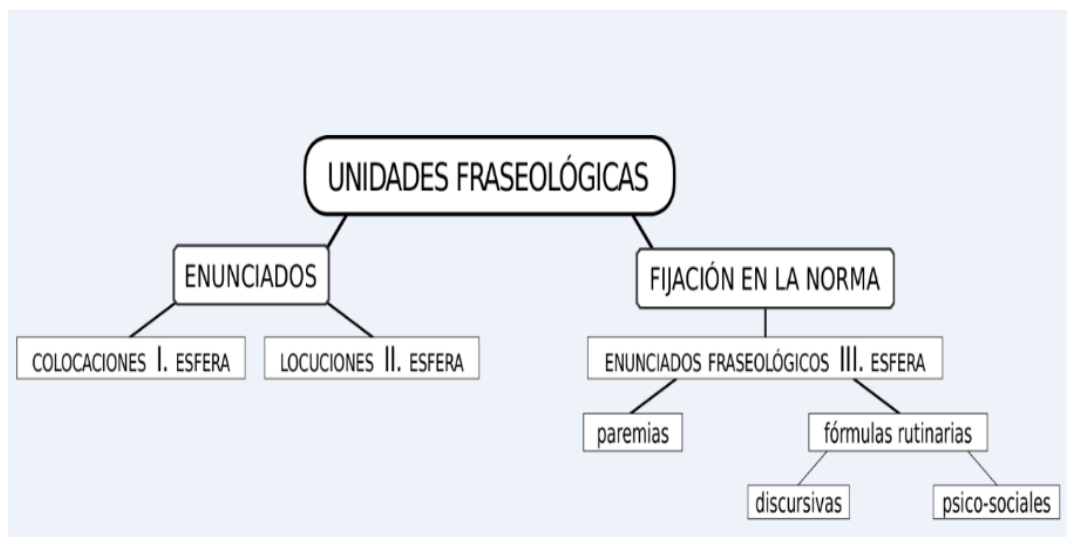

\section{Esquema 2: Clasificación de las unidades fraseológicas}

a. I esfera, está formada por colocaciones o acto de habla no completos regidas por las normas de la lengua, pero con distinto grado de fijación según las normas de uso. Su grado de restricción combinatoria es menor 
que las unidades fraseológicas de la II y III esfera. Las colocaciones pueden ser según estas categorías gramaticales:

- Colocaciones:

- V + S (sujeto) $\rightarrow$ Cosechar frutos - Récolter les fruits

- $\mathbf{V}+$ (Prep.) + S (objeto) $\rightarrow$ Jugar un papel - Jouer un rôle

- Adj./S + S $\rightarrow$ Largo plazo - Long terme

- $\mathbf{S}+$ Prep. $+\mathbf{S} \rightarrow$ Encuesta de satisfacción - Sondage de satisfaction $\rightarrow$ Acuerdo de crédito - Contrat de crédit

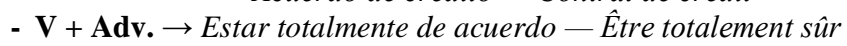

- Adj. + Adv. $\rightarrow$ Drásticamente disminuida - Considérablement diminué

b. II. esfera, son las locuciones o actos de habla que son sintagmas fijos formados por combinaciones de palabras cuyo significado no equivale a la suma de los componentes, sino que significan en bloque y suelen funcionar como palabras o sintagmas; por lo cual adquieren un carácter idiomático. Las locuciones pueden ser.

- Locaciones:

- nominales $\rightarrow$ Piedra angular - Pierre angulaire

$\rightarrow$ Tabla de salvación - Planche de salut

- adjetivas $\rightarrow$ Puntos a favor - Points en faveur

$\rightarrow$ Blanco como la nieve - Blanc comme neige

$\rightarrow$ Sano y salvo - Sain et sauf

- adverbiales $\rightarrow$ A la hora de - Au moment de

$\rightarrow$ De mal en peor - De pire en pire / de mal en pis

- verbales $\rightarrow$ Ir y venir - Aller et venir

- conjuntivas $\rightarrow$ Por consiguiente - Par conséquent

$\rightarrow$ Por si acaso - Au cas où / juste au cas

- preposicionales $\rightarrow$ En cuestión de - En matière de

c. III esfera, son actos de habla equivalentes a un enunciado completo, paremias y fórmulas rutinarias.

- Paremias: sirven para convencer, persuadir e instruir al receptor.

- enunciados de valor específico $\rightarrow$ Estar por el piso - Etre par terre

- citas $\rightarrow$ Como dice aquel - comme on dit

$\rightarrow$ De noche todos los gatos son pardos - la nuit tous les chats sont gris

- refranes $\rightarrow$ Ser una piedra en el zapato - Etre une pierre dans la chaussure

- Fórmulas rutinarias: carecen de autonomía textual y se utilizan en el discurso o en actos de habla determinados de tipo social, expresivo o discursivo y facilitan la interacción, obedecen a las normas de un determinado grupo humano, histórica y geográficamente determinado, su utilización es un equivalente de cortesía y buena educación. Según Corpas (1996: 173) «regulan situaciones emocionales y reacciones en situaciones sociales y facilitan la selección de medios comunicativos en la producción lingüística, proporcionando los instrumentos verbales adecuados y reduciendo, de este modo, la complejidad de la interacción social». Pueden ser:

- discursivas de:

- apertura y cierre $\rightarrow$ ¿Qué hay de nuevo? - Quoi de neuf? 
- psico-sociales:

$\rightarrow$ Vaya con Dios - Que Dieu te garde

$\rightarrow$ Buen provecho - Bon appétit

1. expresivas:

- disculpa $\rightarrow$ Discúlpame - Excusez-moi

$\rightarrow$ Por favor $-S^{\prime}$ 'il vous plaît

- consentimiento $\rightarrow$ ¡Eso es cierto! - C'est certain!

$\rightarrow$ Por supuesto - Bien entendu...

- recusación $\rightarrow$ Ni hablar - Pas même parler

$\rightarrow$ ¡Lo que nos faltaba! - Ça nous manquait!

- agradecimiento $\rightarrow$ Dios se lo pague - Dieu le paie

$\rightarrow$ ¡Muy amable! - Ah, bien merci!

- desear suerte $\rightarrow$ iQue te vaya bonito! - Passez une bonne journée!

- solidaridad $\rightarrow$ Lo acompaño en su pena - Je vous accompagne dans votre chagrin

2. comisivas:

- promesa y amenaza $\rightarrow$ Quien siembra viento recoge tempestades

3. directivas: - Qui sème le vent récolte la tempête

- exhortación $\rightarrow$ ¡Cuidado con el perro! - Attention au chien!

- información $\rightarrow$ Tú dirás - Tu diras

$\rightarrow$ Cómo lo diría yo - Comment dire...

- ánimo $\rightarrow$ No es para tanto - Ce n'est pas si grave/C'est pas grave

4. asertivas:

- aseveración $\rightarrow$ Palabra de honor - Parole d' honneur

$\rightarrow$ Que me parta un rayo - Que la foudre me fasse disparaître

- emocionales $\rightarrow$ ¡Me importa un comino! - Je m'en fous!

5. rituales:

- saludo $\rightarrow$ ¿Qué te trae por aqui? - Quel bon vent t'amène?

- despedida $\rightarrow$ Un saludo cordial — Cordialement/Un cordial salut

\section{Características de la publicación periodística "La Nota Económica"}

Para la realización de la parte práctica de este artículo, hemos trabajado con la revista La Nota Económica, revista de economía colombiana. Esta fue fundada en 1993 y se especializa en el análisis económico y la investigación empresarial, su principal objetivo es brindar una guía útil sobre cómo interactuar y aprovechar las ventajas de los motores económicos en Colombia. Está dirigida tanto a empresas de todos los sectores económicos, a las pymes y a todo aquel que se quiera informar y actualizar sobre la actividad económica del país. La revista, cada mes, dedica su edición a uno de los sectores de mayor importan económica en el país. En su contenido ofrece a sus lectores clasificaciones financieras de los diferentes sectores económicos nacionales. Presenta proyecciones macroeconómicas nacionales e internacionales. Proporciona diferentes estadísticas financieras y económicas. Los textos están redactados con términos claros, sencillos, pero también con términos especializados, Los textos son directos, efectivos y con precisión. Para llamar la atención del lector utilizan algunos rasgos del lenguaje literario que se manifiesta en el uso metáforas y refranes. La revista se presenta en un formato A4 y su maquetación está elaborada con una cuatricromía que da a las fotografías y esquemas una gran matización de colores. 


\section{Análisis y extracción de léxico especializado en la publicación La Nota Económica}

Nuestro objetivo ha sido analizar y extraer términos especializados en sectores económicos, principalmente según los criterios en la motivación externa en la formación de palabras, préstamos, lingüísticos, extranjerismos, y unidades fraseológicas presentes en la revista La Nota Económica del mes de julio de 2017, dedicada al sector de Minas y Energía. En esta edición el contenido está dividido en cinco secciones: Análisis, Secciones Fijas, Tema Central, Artículos de apoyo y Opinión. Estas a su vez están compuestas por varios artículos, todos relacionados con el tema central. El contenido está presentado en 96 páginas, en las que también se pueden ver algunas propagandas publicitarias.

Para el análisis y extracción de términos, hemos leído todos los artículos y de forma sistematizada, hemos clasificado las palabras según las características en la formación de palabras mencionadas en el segundo apartado de este artículo.

\begin{tabular}{|l|l|}
\hline \multicolumn{2}{|l|}{ Préstamo lingüístico, extranjerismos } \\
\hline Francés & clichlé \\
\hline Griego & $\begin{array}{l}\text { telescopio, asteroide, ecosistema, farmacéutico, icónico, } \\
\text { hidráulica, tecnología, bioetanol, neurofocus, análisis, } \\
\text { dicotomía, bidroenergía, biodisél, hidrocarburo, } \\
\text { autosuficiente, megaproyecto, } \\
\text { anticonstitucional biocombustible, }\end{array}$ \\
\hline Latín & $\begin{array}{l}\text { latente, rutenio, osmio, rodio, paladio, iridio, restricción, } \\
\text { solvencia, prioridad, álgida, flagelo, ítem, agro, } \\
\text { infraestructura, prioritario, desértico, innovación, centígrado, } \\
\text { lombustión, statu quo, emisión, mitigar, colapso, híbrido, } \\
\text { homo sapiens, omnipresente, contienda, invalidar, subsuelo, } \\
\text { quid, supervivencia, grosso modo, emporio, incandescente, } \\
\text { ecoturismo, supervivir }\end{array}$ \\
\hline Inglés & $\begin{array}{l}\text { boom, commodities, clúste, resiliencia, biomasa, gasolina, } \\
\text { spot, fracking, ranking, estándar, expertise, offshore, near field } \\
\text { exploration, government take }\end{array}$ \\
\hline Chebótica \\
\hline Alemán & \begin{tabular}{l} 
disél \\
\hline Árabe
\end{tabular} alcohol, sucroquímica \\
\hline
\end{tabular}

\begin{tabular}{|l|}
\hline \multicolumn{1}{|c|}{ Metáforas } \\
\hline ....avanzar a pasos agigantados \\
\hline ...puñado de empresarios \\
\hline ...traído de los cabellos \\
\hline ...rodar la cabeza de... \\
\hline ...entre los tres gigantes \\
\hline ...cuello de botella... \\
\hline ....aguantar este chaparrón... \\
\hline
\end{tabular}




\begin{tabular}{|l|}
\hline ...descalabro de los precios \\
\hline migrar hacia nuevas tecnologías \\
\hline .... pasos agigantados \\
\hline ...puñado de empresarios \\
\hline Oro negro \\
\hline
\end{tabular}

\begin{tabular}{|l|}
\hline \multicolumn{1}{|c|}{ Expresiones fraseológicas } \\
\hline Comer cuento \\
\hline Dejar con la boca abierta \\
\hline Echarse para atrás \\
\hline Mucha agua ha corrido por debajo del molino \\
\hline Entrar en vigencia \\
\hline Una parte del pastel \\
\hline En la otra esquina \\
\hline Hacer frente \\
\hline Ir de la mano \\
\hline Poner en evidencia \\
\hline Llevar la delantera \\
\hline De primera mano \\
\hline La hora cero \\
\hline Pisar los callos \\
\hline Ponerse las pilas \\
\hline Valer la pena \\
\hline Al fin y al cabo \\
\hline Que entre el diablo y escoja \\
\hline Hoy por hoy \\
\hline Luz verde \\
\hline Dejar mal sabor de boca \\
\hline Voltear la moneda \\
\hline Entrar en juego \\
\hline Dejar de lado \\
\hline Mala fortuna \\
\hline
\end{tabular}




\begin{tabular}{|l|}
\hline Tarea titánica \\
\hline Esfumarse de un brochazo \\
\hline Dar una mano \\
\hline Una piedra en el zapato \\
\hline
\end{tabular}

Después de tener una lista con 348 palabras hemos creado un corpus para el análisis de las palabras según las características de la formación de palabras. Nuestra atención la hemos centrado en la formación de palabras por motivación externa. Hemos encontrado 12 metáforas y 29 unidades fraseológicas (colocaciones, locuciones, enunciados fraseológicos). Respeto a préstamos o extranjerismos hemos hallado un total de 78 términos. Con un mayor número de representación, hemos encontrado términos en latín (36), griego (19), inglés (14), alemán (1), árabe (1), checo (1), y francés (1). Entre las palabras del latín y el griego también hemos incluido algunas con sufijos de estos idiomas.

\section{Conclusión}

Para concluir nos gustaría decir que una lengua está en constante movimiento y por el contacto con otras lenguas permite el enriquecimiento del léxico en diferentes sectores como por ejemplo la medicina, la tecnología, la economía, etc. Este enriquecimiento del léxico es mediante la formación de nuevas palabras ya sea por motivación interna o externa. El lenguaje empresarial y financiero se adapta, particularmente en la prensa económica, al receptor semiprofesional a través de una serie de estrategias léxicas y comunicativas, como el uso de términos más generales, construcciones metafóricas, paráfrasis y construcciones explicativas y aclaratorias. Las técnicas a menudo se reemplazan por hiperónimos más generales. Las metáforas y las expresiones idiomáticas se usan actualmente no solo en estilos coloquiales y literarios, sino que aparecen cada vez más en la ciencia popular o incluso vocacional (por ejemplo, lenguaje económico o político). Su objetivo es involucrar al lector o al oyente, acercarlos a lo hablado o descrito, hacer que el texto o el discurso sean más atractivos, etc. Spišiaková M. (2018: 51).

En nuestro trabajo hemos presentado una clasificación sencilla y clara sobre la formación de palabras por motivación externa en los idiomas español y francés. Para la parte práctica hemos trabajado solo con el español, para esto hemos elegido el sector de la economía, minas y energía al cual está dedicada la edición del mes de julio, 2017, de la revista La Nota Económica. En ella hemos encontrado un alto número de términos especializados que se han creado por medio de formación de palabras, ofreciendo un enriquecimiento léxico provocado tanto por la motivación interna como a la externa. También hay que destacar que los artículos de dicha publicación sirven como material didáctico que puede ser de interés para los estudiantes español como una lengua extranjera.

Tento príspevok je súčast'ou riešenia grantového projektu KEGA/Inovácia jazykovej prípravy ekonómov, diplomatov a kultúrnych mediátorov - digitálna učebnica španielskeho jazyka zameraná na odbornú prax 007EU-4/2018

\section{Bibliographic references}

ALVAR EZQUERRA, M. 1993. El neologismo español actual. In: Léxico español actual: Actas del I Congreso internacional de léxico español actual, Venecia-Treviso, 14-15 de marzo de 2005 / coord. por Luis Luque Toro, 2007, ISBN 9788875431808 , pp. $11-36$

XLinguae, Volume 13 Issue 1, January 2020, ISSN 1337-8384, eISSN 2453-711X 
Available

online:

https://ispsfrey-

cha.infd.edu.ar/sitio/upload/Alvar_Exquerra_Neologismo_en_el_espaniol_actual.pdf CORPAS PASTOR, G. 1996. Manual de fraseología española. Madrid: Gredos.

GOMEZ CAPUZ, J. 2009. El tratamiento del préstamo lingüístico y el calco en los libros de texto de bachillerato y en las obras divulgativas. In REVISTA ELECTRÓNICA DE ESTUDIOS FILOLÓGICOS. n. XVII, ISSN 1577 - 6921

Avialable online: https://dialnet.unirioja.es/revista/4271/A/2009

JIRON ERWENNE, C. 2008. La enseñanza de unidades fraseológicas en diálogos situacionales. Aula Diez español Available online. http://www.auladiez.com/didactica/FONTE-TrabajoFinalCarmenJironErwenne.pdf (29.10.2017)

MOTERO MARTINEZ, S. 2003. Estructuración conceptual y formalización terminográfica de frasemas en el subdominio de la oncología

Available online: http://www.cervantesvirtual.com/obra/estructuracion-conceptual-yformalizacion-

terminografica-de-frasemas-en-el-subdominio-de-la-oncologia--0/ (25.10.2017)

REAL ACADEMIA ESPAÑOLA. 2014. Diccionario de la lengua española. 23. ${ }^{a}$ ed. [En línea]. Madrid: Espasa Calpe, S. A.

ROMERO GANUZA, P. 2006 La delimitación de las unidades fraseológicas (UF) en la investigación alemana y española. Interlingüística, ISSN 1134-8941, n. 17, pp. 905914, Available online: https://dialnet.unirioja.es/servlet/articulo?codigo=2317697

REVISTA LA NOTA ECONÓMICA: Minas y energía. La nueva realidad de la minería espacial. ¿Quiénes están detrás del negocio? Julio 2017

SCIUTO, V. 2005. Unidades fraseológicas: un análisis contrastivo de los somatismos del español de Argentina y del italiano. AISPI. Actas XXII. Available online:

https://cvc.cervantes.es/literatura/aispi/pdf/22/II_31.pdf

URRUTIA, C. H. - CANDIA, G. L. 1997. La formación de palabras en el español actual:Perspectivas metodológicas. ONOMÁYEIN, n. 2 Revista de lingüística, filología y traducción, Available online: http://onomazein.letras.uc.cl/03_Numeros/N2/N2.html

SPISIAKOVA, M. 2018. Súčasný španielsky ekonomický jazyk. In Lingua et vita: vedecký časopis pre výskum jazykov a interkultúrnej komunikácie. - Bratislava: EKONOM, vol. 7, n. 13, pp. 42-54, ISSN 1338-6743, KEGA 007EU-4/2018.

VALE CANDELAS, J. 2014. Los préstamos en español actual: Un estudio sociolingüístico y de corpus. Trabajo de fin de grado. Universitat Rovira i Virgili

Words: 4921

Characters: 33289 (18,49 standard pages)

Mgr. Diana Patricia Varela Cano, PhD.

Department of Romance and Slavic Languages

Faculty of Applied Languages

University of Economics in Bratislava

Dolnozemská cesta 1

85235 Bratislava

Slovakia

diana.varelacano@euba.sk 